\title{
Metabolically healthy obesity and risk of stroke: a meta-analysis of prospective cohort studies
}

\author{
Ling-Zhi Ma ${ }^{1}$, Fu-Rong Sun ${ }^{1}$, Zuo-Teng Wang ${ }^{1}$, Lin Tan ${ }^{1}$, Xiao-He Hou ${ }^{1}$, Ya-Nan Ou ${ }^{1}$, Qiang Dong ${ }^{2}$, \\ Jin-Tai Yu' ${ }^{2}$, Lan Tan ${ }^{1}$ \\ ${ }^{1}$ Department of Neurology, Qingdao Municipal Hospital, Qingdao University, Qingdao, China; ${ }^{2}$ Department of Neurology and Institute of \\ Neurology, Huashan Hospital, Shanghai Medical College, Fudan University, Shanghai, China \\ Contributions: (I) Conception and design: LZ Ma, FR Sun, ZT Wang, L Tan, XH Hou, YN Ou, JT Yu; (II) Administrative support: L Tan, JT Yu; (III) \\ Provision of study materials or patients: LZ Ma, JT Yu; (IV) Collection and assembly of data: LZ Ma, FR Sun, ZT Wang, L Tan, XH Hou, YN Ou, \\ Q Dong, JT Yu; (V) Data analysis and interpretation: LZ Ma, JT Yu; (VI) Manuscript writing: All authors; (VII) Final approval of manuscript: All \\ authors. \\ Correspondence to: Prof. Jin-Tai Yu, MD, PhD. Department of Neurology and Institute of Neurology, Huashan Hospital, Shanghai Medical College, \\ Fudan University, 12th Wulumuqi Zhong Road, Shanghai 200040, China. Email: jintai_yu@fudan.edu.cn; Prof. Lan Tan, MD, PhD. Department of \\ Neurology, Qingdao Municipal Hospital, Qingdao University, Qingdao 266071, China. Email: dr.tanlan@163.com.
}

\begin{abstract}
Background: Metabolic healthy obesity (MHO) is a unique subgroup of overweight and obese individuals with normal metabolic characteristics. Its association with the risk of stroke remains unclear. We aimed to examine the risk of stroke in MHO individuals and the further associations between stroke and metabolic abnormalities under different bodyweight conditions.

Methods: We systematically searched PubMed, Embase and Cochrane Library from December 1946 to January 2019, and only included prospective cohort studies. Random effects models were used to evaluate the pooled risk ratios (RR) and $95 \%$ confidence intervals (95\% CI) of incident stroke.

Results: A total of eight studies comprising 4,256,888 participants were included in the meta-analysis. MHO individuals had an increased risk of stroke compared with metabolically healthy normal weight (MH-NW) individuals ( $\mathrm{RR}=1.17,95 \% \mathrm{CI}: 1.11-1.23)$. However, the stroke risk of metabolically healthy overweight individuals was the same ( $\mathrm{RR}=1.02,95 \% \mathrm{CI}: 0.84-1.23)$. All groups with unhealthy metabolism had a similarly elevated risk: normal weight $(\mathrm{RR}=1.83,95 \% \mathrm{CI}: 1.57-2.14)$, overweight ( $\mathrm{RR}=1.93,95 \% \mathrm{CI}$ : 1.44-2.58), and obesity (RR =2.00, 95\% CI: 1.40-2.87).
\end{abstract}

Conclusions: The meta-analysis confirms a positive association between MHO phenotype and the risk of stroke. Individuals with metabolic abnormalities under different bodyweight conditions are at elevated risk.

Keywords: Metabolism; obesity; stroke; meta-analysis, prospective cohort

Submitted May 31, 2020. Accepted for publication Nov 08, 2020.

doi: $10.21037 /$ atm-20-4387

View this article at: http://dx.doi.org/10.21037/atm-20-4387

\section{Introduction}

Stroke accounts for approximately $10 \%$ of global mortality (1), and ranks as the second most common cause of death (2). Obesity and metabolic syndrome (Mets), which often co-exist, are associated with an increased risk of stroke $(3,4)$. However, quite a few studies reported that obesity might confer a beneficial effect on individuals with stroke
(5-7). The complexity of the association between body mass index (BMI) and stroke may be presumably attributed to the heterogeneity of obese phenotypes: unhealthy or healthy metabolic status. A significant proportion of subjects with obesity do not develop Mets. On the contrary, Mets can be present in normal weight individuals (8). Therefore, it has been increasingly essential to distinguish 
between obese individuals at a high risk of obesityrelated metabolic diseases and metabolically "healthy" obese individuals. Correspondingly, the population can be divided into 6 subtypes according to BMI and metabolic status: metabolically healthy normal weight (MH-NW), metabolically healthy overweight (MH-OW), metabolically healthy obese (MHO), metabolically unhealthy normal weight (MU-NW), metabolically unhealthy overweight (MU-OW), and metabolically unhealthy obese (MUO) (8).

Obese individuals without metabolic complications, such as elevated blood pressure, elevated triglycerides, reduced high-density lipoprotein cholesterol (HDL-C) and diabetes, are known as MHO individuals. Despite the excessive weight, $\mathrm{MHO}$ displays a beneficial hormonal profile, a favorable metabolic profile characterized by higher insulin sensitivity, a favorable immune profile, and reduced inflammation $(8,9)$. Some studies have confirmed that $\mathrm{MHO}$ has a protective effect and does not increase the risk of cardiovascular diseases (CVDs) and mortality, especially when compared with at-risk obesity $(10,11)$. Several other studies have shown that compared with $\mathrm{MH}-$ NW individuals, the MHO group has higher incidences of CVD, cancer, and mortality (12-14). However, whether $\mathrm{MHO}$ is associated with an excess risk of stroke remains a subject of debate due to lack of evidence. Previous studies on the effects of the BMI-metabolic status phenotypes on stroke morbidity have produced conflicting results $(15,16)$.

It remains unclear whether $\mathrm{MHO}$ is associated with an excess risk of stroke. Thus, we conducted this meta-analysis which only included prospective cohorts to explore the associations of stroke risk with the BMI-metabolic status phenotypes, especially the MHO subtype. We present the following article in accordance with the PRISMA reporting checklist (available at http://dx.doi.org/10.21037/atm-204387).

\section{Methods}

\section{Search strategy and selection criteria}

We complied with the recommendations made by the MetaAnalysis of Observational Studies in Epidemiology Group, the 2009 guidelines of Preferred Reporting Items for Systematic Reviews and Meta-Analyses (PRISMA) $(17,18)$. PubMed, Embase and Cochrane Library were thoroughly searched from December 1946 to January 2019. The following scientific search strategy was used: ("stroke" OR "cerebrovascular" OR "cerebral” OR "transient ischemic attack" OR "TIA" OR "hemorrhage" OR "hemorrhagic") AND ("Metabolic*" OR "metabolism") AND ("obese" OR "obesity" OR "overweight" OR "BMI" OR "body mass index" OR "waist circumstance"). We also manually searched the biographies of eligible studies and related meta-analyses to find possible missing studies.

We included studies that simultaneously met the following criteria: (I) they were conducted in adults; (II) they were prospective cohort studies; (III) participants were stroke-free at baseline; (IV) according to BMI, they categorized participants into three groups, normal weight (BMI $<25 \mathrm{~kg} / \mathrm{m}^{2}$ ), overweight (BMI $\geq 25$ and $<30 \mathrm{~kg} / \mathrm{m}^{2}$ ), and obesity (BMI $\geq 30 \mathrm{~kg} / \mathrm{m}^{2}$ ), or into two groups, normal weight $\left(\right.$ BMI $\left.<25 \mathrm{~kg} / \mathrm{m}^{2}\right)$ and abnormal weight $\left(\mathrm{BMI} \geq 25 \mathrm{~kg} / \mathrm{m}^{2}\right)$. A threshold of $24 \mathrm{~kg} / \mathrm{m}^{2}$ was set for Asians; (V) they further classified participants according to healthy or unhealthy metabolic status; (VI) they defined $\mathrm{MHO}$ as individuals with less than two common metabolic complications of obesity, such as elevated blood pressure, high triglycerides, decreased HDL-C and diabetes. Studies which met one of the following criteria were excluded: (I) the article was not published in English; (II) the normal weight was defined as BMI $<30 \mathrm{~kg} / \mathrm{m}^{2}$; (III) stroke was not treated as a single outcome. We only included the updated study for overlapping studies. In addition, studies were excluded if their risk ratios (RRs) and 95\% confidence intervals (95\% CIs) were not accessible even after contacting the authors.

\section{Data extraction and quality assessment}

The following detailed information was extracted carefully from each study, including authors' name, publication dates, follow-up periods, countries, cohort sources, ages at baseline, gender ratios, sample sizes, case numbers, BMI categories, definitions of metabolic status, BMI-metabolic status phenotypes, adjusted confounders, outcome events, effect sizes, and $95 \%$ CIs. For studies without reported risk estimates, raw data, if available, were used to calculate effect sizes. Details of all included studies are shown in Table 1.

Quality assessments of all potentially eligible studies were conducted using the Newcastle-Ottawa Scale (NOS) (Table S1) (19), which contains 8 items categorized into 3 domains: selection, comparability, and exposure. No studies were excluded due to their low quality scores. Data extraction and quality evaluation were conducted by two independent authors, and any disagreement was resolved by consensus with a third author. 
Table 1 Characteristics of included studies

\begin{tabular}{|c|c|c|c|c|c|c|c|c|}
\hline Author, country; Cohort & $\begin{array}{l}\text { Follow-up years; sample size/incident } \\
\text { case; sex, \%male; age (years) }\end{array}$ & Categories of BMI $\left(\mathrm{kg} / \mathrm{m}^{2}\right)$ & Definition of metabolic status & Covariates & Type of stroke & $\begin{array}{l}\text { Divide participants } \\
\text { into } 4 \text { or } 6 \text { groups }\end{array}$ & RRs/HRs (95\% Cls) & $\begin{array}{l}\text { Quality } \\
\text { score }\end{array}$ \\
\hline \multirow{5}{*}{$\begin{array}{l}\text { Song, 2007, USA: } \\
\text { Women's Health Study }\end{array}$} & \multirow{5}{*}{$8.8 ; 25,626 / 256 ; 0 ; 54.6$} & \multirow{5}{*}{$\begin{array}{l}\text { Normal: }<25 \text {, overweight: } \\
25-29.9 \text {, obese: } \geq 30\end{array}$} & \multirow{5}{*}{$\begin{array}{l}\text { A metabolically healthy state was considered if } \leq 2 \text { of the metabolic } \\
\text { factors (ATPIII criterion): (I) BP } \geq 135 / 85 \mathrm{mmHg} \text {; (II) triglycerides } \\
\geq 150 \mathrm{mg} / \mathrm{dL} ; \text { (III) HDL cholesterol }<50 \mathrm{mg} / \mathrm{dL} \text {; (IV) fasting glucose } \\
\geq 110 \mathrm{mg} / \mathrm{dL}\end{array}$} & \multirow{5}{*}{$\begin{array}{l}\text { Age, randomized treatment assignment } \\
\text { in the Women's Health Study, smoking, } \\
\text { exercise, alcohol intake, total calorie intake, } \\
\text { postmenopausal hormone use, multivitamin } \\
\text { use, parental history of myocardial } \\
\text { infarction before } 60 \text { year }\end{array}$} & \multirow{5}{*}{ Stroke } & MH-NW & 1 (ref) & \multirow[t]{5}{*}{9} \\
\hline & & & & & & MH-OW & $0.83(0.58-1.18)$ & \\
\hline & & & & & & MHO & $1.13(0.70-1.82)$ & \\
\hline & & & & & & MU-OW & $1.74(1.05-2.87)$ & \\
\hline & & & & & & MUO & $1.49(0.86-2.58)$ & \\
\hline \multirow{6}{*}{$\begin{array}{l}\text { Hinnouho, 2015, UK: } \\
\text { Whitehall II study }\end{array}$} & \multirow[t]{6}{*}{$17.4 ; 7,122 / 118 ; 69.7 ; 49.3$} & \multirow{6}{*}{$\begin{array}{l}\text { Normal: }<25 \text {, overweight: } \\
\text { 25-29.9, obese: } \geq 30\end{array}$} & \multirow{6}{*}{$\begin{array}{l}\text { A metabolically healthy state was considered if none or one of the } \\
\text { metabolic factors (ATPIII criterion): (I) SBP } \geq 130 \mathrm{mmHg} \text { or DBP } \\
\geq 85 \mathrm{mmHg} \text { or under medical treatment; (II) triglycerides } \\
(\geq 1.7 \mathrm{mmol} / \mathrm{L} \text { ) or under medical treatment; (III) HDL cholesterol } \\
1.104 \mathrm{mmm} / \mathrm{L} \text { in men and } 1.29 \mathrm{mmol} / \mathrm{L} \text { in women; (IV) fasting glucose } \\
(\geq 5.6 \mathrm{mmol} / \mathrm{L} \text { ) or under medical treatment }\end{array}$} & \multirow{6}{*}{$\begin{array}{l}\text { Sex, socioeconomic status, marital status, } \\
\text { ethnicity, physical activity, smoking, } \\
\text { alcohol, fruits, vegetables consumption, } \\
\text { CVD medication, procedures }\end{array}$} & \multirow{6}{*}{$\begin{array}{l}\text { One of subarachnoid hemorrhage, } \\
\text { intracerebral hemorrhage, cerebral } \\
\text { infarction, and not specified } \\
\text { stroke and transient cerebral } \\
\text { ischemic attacks }\end{array}$} & MH-NW & 1 (ref) & \multirow[t]{6}{*}{8} \\
\hline & & & & & & MH-OW & $0.59(0.32-1.09)$ & \\
\hline & & & & & & MHO & $1.59(0.68-3.70)$ & \\
\hline & & & & & & MU-NW & $1.82(1.03-3.22)$ & \\
\hline & & & & & & MU-OW & $2.05(1.29-3.26)$ & \\
\hline & & & & & & MUO & $2.15(1.12-4.14)$ & \\
\hline \multirow{4}{*}{$\begin{array}{l}\text { Andersen, 2015, } \\
\text { Denmark: Danish Medical } \\
\text { Birth Register }\end{array}$} & \multirow[t]{4}{*}{$5.6 ; 261,489 / \mathrm{NA} ; 0 ; 30.5$} & \multirow{4}{*}{$\begin{array}{l}\text { Normal: }<25 \text {, abnormal } \\
\text { weight: } 225\end{array}$} & \multirow{4}{*}{$\begin{array}{l}\text { A metabolically healthy state was considered if none of the } \\
\text { metabolic factors: (I) hypertension: a registered diagnosis of } \\
\text { hypertension in the National Patient Register (ICD-10 = DI10-D115) } \\
\text { plus at least one claimed prescription for an antihypertensive } \\
\text { agent within } 90 \text { days, or claims of at teast two separate types of } \\
\text { antihypertensive agents within } 90 \text { days; (II) dyslipidemia: claim of } \\
\text { a prescription for a lipid-lowering drug; (III) diabetes: either (i) two } \\
\text { separate prescription claims of glucose-lowering agents within } \\
6 \text { months (classifying individuallas as having diabetes from the date } \\
\text { of the second prescription claim), or (ii) a new entry in the National } \\
\text { Patient Register with a diagnosis of diabetes }\end{array}$} & \multirow[t]{4}{*}{ Age, calendar year, smoking } & \multirow[t]{4}{*}{ Ischemic stroke } & MH-NW & 1 (reff) & \multirow[t]{4}{*}{8} \\
\hline & & & & & & МHO & $0.99(0.77-1.26)$ & \\
\hline & & & & & & MU-NW & $1.88(1.24-2.85)$ & \\
\hline & & & & & & MuO & $1.87(1.30-2.71)$ & \\
\hline \multirow[t]{6}{*}{ Guo, 2016, USA: ARIC } & \multirow[t]{6}{*}{$18.7 ; 14,685 / 1,044 ; 45.6 ; 54.3$} & \multirow{6}{*}{$\begin{array}{l}\text { Normal: }<25 \text {, overweight: } \\
25-29.9 \text {, obese: } \geq 30\end{array}$} & \multirow{6}{*}{$\begin{array}{l}\text { A metabolically healthy state was considered if } \leq 2 \text { of the metabolic } \\
\text { factors (ATPIII criterion): (I) } S B P \geq 130 \mathrm{mmHg} \text { or DBP } \geq 85 \mathrm{mmHg} \text {; } \\
\text { (II) untreated total cholesterol } \geq 240 \mathrm{mg} / \mathrm{dL} \text { and } \mathrm{HDL}<40 \mathrm{mg} / \mathrm{dl} \text { in } \\
\text { men and }<50 \mathrm{mg} / \mathrm{dL} \text { in women; (III) untreated fasting } \geq 100 \mathrm{mg} / \mathrm{dL} \text { or } \\
\text { HbA1c } \geq 5.7 \%\end{array}$} & \multirow{6}{*}{$\begin{array}{l}\text { Age, sex, race, income, education, tobacco } \\
\text { smoking, alcohol drinking }\end{array}$} & \multirow{6}{*}{ Stroke } & MH-NW & 1 (ref) & \multirow[t]{6}{*}{8} \\
\hline & & & & & & MH-OW & $1.31(0.38-4.49)$ & \\
\hline & & & & & & MHO & $0.85(0.36-2.04)$ & \\
\hline & & & & & & MU-NW & $2.45(0.71-8.44)$ & \\
\hline & & & & & & MU-OW & $3.92(1.19-12.94)$ & \\
\hline & & & & & & MUO & $3.87(1.17-12.77)$ & \\
\hline
\end{tabular}

Table 1 (continued) 
Table 1 (continued)

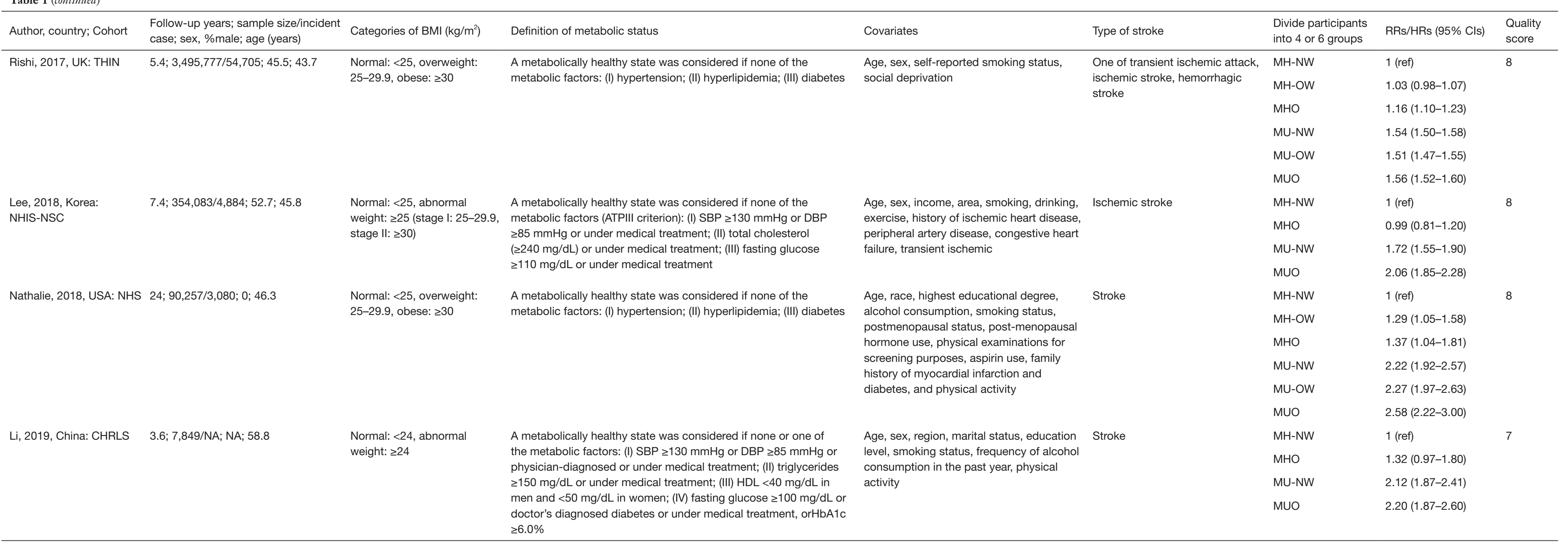

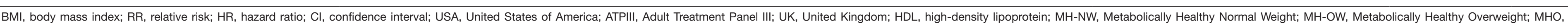

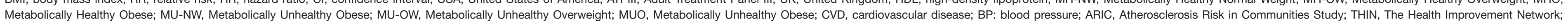
Metabolically Healthy Obese; MU-NW, Metabolically Unhealthy Obese; MU-OW, Metabolically Unhealthy Overweight; MUO, Metabolically Unhealthy Obese;
NHIS-NSC, National Health Insurance Service-National Sample Cohort; NHS, Nurses' Health Study; CHRLS, China Health and Retirement Longitudinal Study. 


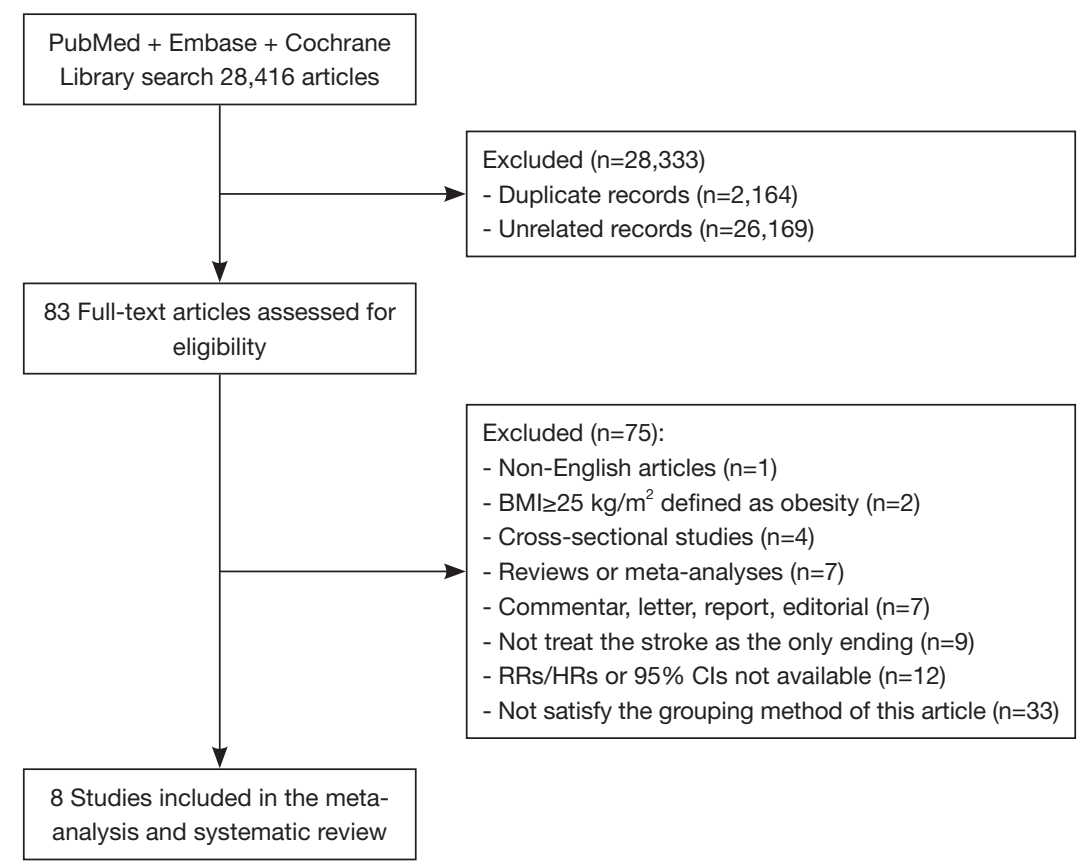

Figure 1 Flowchart of study selection. CVD, cardiovascular disease; BMI, body mass index.

\section{Statistical analysis}

Overall RRs were calculated to assess the risk for $\mathrm{MH}-\mathrm{OW}$, MHO, MU-NW, MU-OW, and MUO phenotypes using $\mathrm{MH}-\mathrm{NW}$ participants as the reference group. Due to the significant heterogeneity in subject characteristics across studies, effect sizes and $95 \%$ CIs were calculated using a random effects model (20). We used Cochrane Q test to assess heterogeneity among studies $(20,21)$. Furthermore, we performed sensitivity analyses after excluding one study at a time to assess the reliability and sensitivity of the results. Subgroup analyses according to follow-up duration were conducted to detect the possible sources of heterogeneity (21). Finally, publication bias was adopted to check up if the pooled values were impacted by part of the studies' positive results using Egger's test. When statistically significant bias was found, the trim and fill method was used to adjust it. All statistical tests used a significance level of $\mathrm{P}<0.05$. Statistical analyses were performed using $\mathrm{R}$ 3.6.1.

\section{Results}

Figure 1 shows the flowchart of the study selection. We identified 28,416 studies through electronic searches. Eighty-three studies that may be eligible for inclusion were identified after reviewing titles and abstracts. Eight prospective cohort studies met the inclusion criteria after reviewing the full text $(15,16,22-27)$.

\section{Characteristics of included studies}

Table 1 summarizes the characteristics of studies. Among the included studies, five used Adult Treatment Panel III (ATP III) criteria including elevated blood pressure, higher triglycerides, reduced HDL-C and diabetes, and the other three used medical histories of these diseases to define the metabolic status. The sample size of the studies varied greatly, ranging from 7,122 participants to 3,495,777 participants. The included studies had an average followup time of 11.4 years, and the population had a mean age of 47.9 years. The quality scores of these studies according to the NOS are summarized in Table S1. All studies included in this meta-analysis got at least seven stars, indicating that the quality is acceptable.

\section{Effects of BMI categories on metabolically bealthy population}

In an overall analysis of eight studies involving 4,256,888 participants $(15,16,22-27)$, metabolically healthy individuals with $\mathrm{BMI} \geq 25 \mathrm{~kg} / \mathrm{m}^{2}$ had a higher risk of stroke compared 
with $\mathrm{MH}-\mathrm{NW}$ individuals ( $\mathrm{RR}=1.09,95 \%$ CI: $0.99-1.19$ ) (Figure $2 A)$ with non-significant heterogeneity $\left(\mathrm{I}^{2}=36 \%\right.$, $\mathrm{P}=0.14)$.

\section{Overweight}

In a pooled analysis of five studies involving 3,633,467 participants (16,22-25), no significant association was found between MH-OW and stroke (RR $=1.02$, 95\% CI: 0.84 $1.23)$ (Figure $2 B$ ) with moderate heterogeneity across studies measured by a random-effects model $\left(\mathrm{I}^{2}=57 \%, \mathrm{P}=0.05\right)$. Sensitivity analyses were conducted to explore the sources of heterogeneity; the pooled effect did not vary substantially after excluding any single study (Figure S1). We pooled studies with over 10 years of follow-up to explore the sources of heterogeneity and explore whether the length of follow-up will have an impact on the outcome. The results showed that the stroke risk in $\mathrm{MH}-\mathrm{OW}$ patients was similar to that in $\mathrm{MH}-\mathrm{NW}$ patients, both for long-term follow-up (RR $=0.99,95 \%$ CI: $\left.0.56-1.77, \mathrm{I}^{2}=65 \%, \mathrm{P}=0.06\right)$ and shortterm follow-up ( $\mathrm{RR}=1.00,95 \% \mathrm{CI}: 0.86-1.16, \mathrm{I}^{2}=28 \%$, $\mathrm{P}=0.24$ ) (Figure $\mathrm{S} 2$ ), suggesting follow-up duration was not a source of heterogeneity.

\section{Obesity}

In a pooled analysis of five studies involving 3,633,467 participants (16,22-25), a significant association between $\mathrm{MHO}$ and a higher risk of stroke was found with nonsignificant heterogeneity ( $\mathrm{RR}=1.17,95 \% \mathrm{CI}: 1.11-1.23$, $\mathrm{I}^{2}=0 \%, \mathrm{P}=0.67$ ) (Figure 2C). We performed subgroup analyses according to follow-up duration (more than 10 years or less than 10 years). Compared with the $\mathrm{MH}$ NW phenotype, the pooled RRs of MHO phenotype were extremely higher irrespective of follow-up duration, with their RRs of 1.33 (95\% CI: $1.04-1.72, \mathrm{I}^{2}=0 \%, \mathrm{P}=0.54$ ) for analysis of studies with over 10 years of follow-up (Figure $\mathrm{S} 3 \mathrm{~A}$ ) and 1.16 (95\% CI: $1.10-1.23$, and $\mathrm{I}^{2}=0 \%, \mathrm{P}=0.91$ ) for analysis of studies with less than 10 years of follow-up (Figure S3B) respectively. The results of the funnel plot and Egger test showed that publication biases weren't found in MHO subgroups $(\mathrm{P}=0.632)$ (Figure $\mathrm{S} 4)$. The credibility of result was moderate using GRADEpro GDT (Figure S5).

\section{Effects of BMI categories on metabolically unbealthy individuals}

As expected, all groups with metabolically unhealthy status had a similarly increased risk of stroke. In a pooled analysis of eight studies $(15,16,22-27)$, the MU-NW group had an increased risk of stroke compared to the MH-NW group ( $\mathrm{RR}=1.83$, 95\% CI: $1.57-2.14$ ) (Figure $3 A$ ) with obvious heterogeneity across studies $\left(\mathrm{I}^{2}=86 \%, \mathrm{P}<0.01\right)$. In a pooled analysis of 5 studies, a significant association was found between MU-OW phenotype and a higher risk of stroke $\left(\mathrm{RR}=1.93,95 \% \mathrm{CI}: 1.44-2.58, \mathrm{I}^{2}=88 \%, \mathrm{P}<0.01\right)$ (Figure $3 B$ ), and a similar result was found for MUO phenotype $(\mathrm{RR}=2.00,95 \% \mathrm{CI}: 1.40-2.87)$ (Figure 3C) with obvious heterogeneity across studies $\left(\mathrm{I}^{2}=91 \%, \mathrm{P}<0.01\right)$. Subsequently, sensitivity analyses were conducted to explore the sources of heterogeneity. Finally, the study of THIN (16) fully explained the heterogeneity (Figure S1). After carefully comparing this study with other studies, we found that this study only used the medical history provided by the participants rather than rigorous laboratory tests to determine whether participants had metabolic complications of obesity, such as elevated blood pressure, high triglycerides, decreased HDL-C and diabetes. After excluding this study, the heterogeneities in MU-NW, MU-OW and MUO phenotypes were reduced to $52 \%$, $0 \%$, and $30 \%$, respectively. The pooled effects did not vary substantially after excluding this single study (MUNW: RR $=1.95$, 95\% CI: 1.71-2.22; MU-OW: RR $=2.23$, 95\% CI: 1.95-2.54; MUO: RR =2.30, 95\% CI: $1.73-3.06$ ) (Table S2).

\section{Discussion}

This meta-analysis of prospective studies summarized the inconsistent results from previous studies investigating the associations between BMI-metabolic status phenotypes and stroke risk. There are two critical findings. First, compared with $\mathrm{MH}-\mathrm{NW}$ individuals, $\mathrm{MHO}$ individuals were at an increased risk of stroke. Second, all three unhealthy metabolic status phenotypes showed increased risks, which are not affected by the weight status.

Results suggested that MHO participants were at a higher risk of stroke. And further analyses suggested that regardless of follow-up duration, the MHO phenotype did associate with a higher risk of stroke. $\mathrm{MH}-\mathrm{OW}$ participants were not at an increased risk of stroke compared with $\mathrm{MH}$ NW individuals, although statistical significance was almost reached. However, the results have to be interpreted with caution, as moderate heterogeneity was observed in these analyses. As expected, the three unhealthy metabolic status phenotypes showed higher risks, which are not affected by 
A Study

Song ( Women's Health Study, 2007 )

Hinnouho (Whitehall II study, 2015 )

Andersen ( Medical Birth Register, 2015 )

Guo ( ARIC , 2016 )

Rishi ( THIN, 2017)

Lee (NHIS-NSC, 2018)

Nathalie (NHS, 2018 )

Li ( CHRLS, 2019)

Random effects model

Heterogeneity: $I^{2}=36 \%, \tau^{2}=0.0050, p=0.14$

B Study

Song ( Women's Health Study, 2007) Hinnouho (Whitehall II study, 2015 )

Guo ( ARIC, 2016 )

Rishi (THIN, 2017)

Nathalie (NHS, 2018)

Random effects model

Heterogeneity: $I^{2}=57 \%, \tau^{2}=0.0208, p=0.05$

\section{Study}

Song (Women's Health Study, 2007) Hinnouho (Whitehall II study, 2015 )

Guo ( ARIC , 2016 )

Rishi ( THIN , 2017 )

Nathalie (NHS, 2018)

\section{Random effects model}

Heterogeneity: $I^{2}=0 \%, \tau^{2}=0, p=0.67$

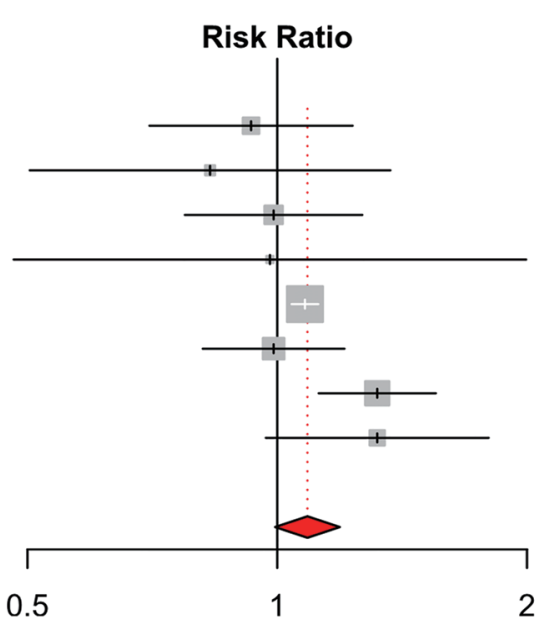

RR $\quad 95 \%-\mathrm{Cl}$ Weight

$0.93[0.70 ; 1.23] \quad 8.1 \%$

$0.83[0.50 ; 1.37] \quad 3.0 \%$

$0.99[0.77 ; 1.27] \quad 10.1 \%$

$0.98[0.48 ; 2.00] \quad 1.5 \%$

$1.08[1.04 ; 1.12] \quad 38.8 \%$

$0.99[0.81 ; 1.20] \quad 13.9 \%$

$1.32[1.12 ; 1.55] \quad 17.6 \%$

$1.32[0.97 ; 1.80] \quad 7.0 \%$

$1.09[0.99 ; 1.19] 100.0 \%$

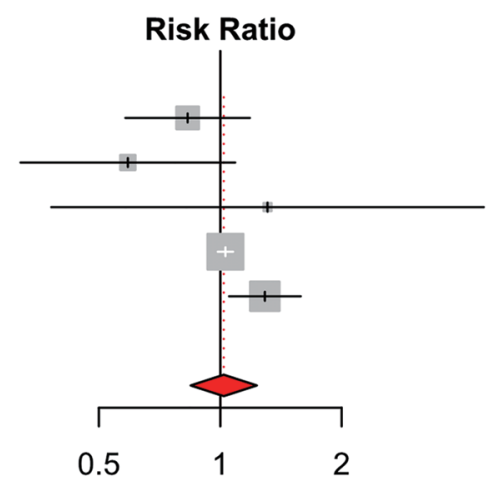

RR $\quad 95 \%-\mathrm{Cl}$ Weight

$0.83[0.58 ; 1.18] \quad 17.3 \%$

$0.59[0.32 ; 1.09] \quad 7.8 \%$

$1.31[0.38 ; 4.50] \quad 2.2 \%$

$1.03[0.99 ; 1.08] \quad 43.4 \%$

$1.29[1.05 ; 1.58] \quad 29.2 \%$

$1.02[0.84 ; 1.23] 100.0 \%$

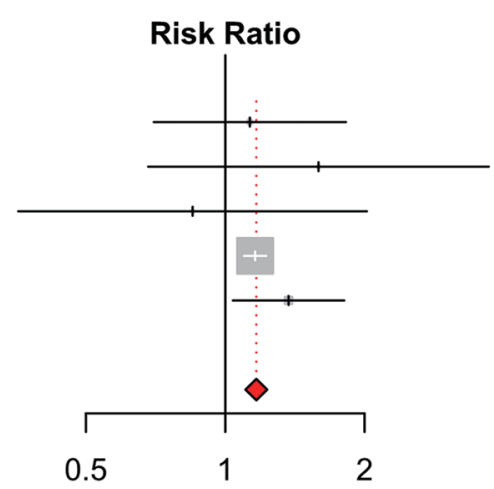

RR $\quad 95 \%-\mathrm{Cl}$ Weight

$1.13[0.70 ; 1.82] \quad 1.3 \%$

$1.59[0.68 ; 3.71] \quad 0.4 \%$

$0.85[0.36 ; 2.02] \quad 0.4 \%$

$1.16[1.10 ; 1.23] \quad 94.1 \%$

$1.37[1.04 ; 1.81] \quad 3.8 \%$

$1.17[1.11 ; 1.23] 100.0 \%$

Figure 2 Meta-analyses of metabolically healthy body mass index categories for the risk of stroke compared with MH-NW individuals. (A) Metabolically healthy and BMI $\geq 25 \mathrm{~kg} / \mathrm{m}^{2}$; (B) metabolically healthy overweight; (C) metabolically healthy obese. ARIC, Atherosclerosis Risk in Communities Study; THIN, The Health Improvement Network; NHIS-NSC, National Health Insurance Service-National Sample Cohort; NHS, Nurses' Health Study; CHRLS, China Health and Retirement Longitudinal Study; MH-NW, metabolically healthy normal weight. 
A Study

Song (Women's Health Study, 2007 ) Hinnouho (Whitehall II study, 2015 ) Andersen (Medical Birth Register , 2015 ) Guo ( ARIC , 2016)

Rishi ( THIN , 2017 )

Lee ( NHIS-NSC, 2018)

Nathalie (NHS, 2018 )

Li ( CHRLS, 2019)

\section{Random effects model}

Heterogeneity: $I^{2}=86 \%, \tau^{2}=0.0280, p<0.01$

B Study

Song ( Women's Health Study, 2007 ) Hinnouho (Whitehall II study, 2015 ) Guo (ARIC, 2016)

Rishi (THIN, 2017)

Nathalie (NHS, 2018 )

Random effects model

Heterogeneity: $I^{2}=88 \%, \tau^{2}=0.0700, p<0.01$

C Study

Song (Women's Health Study, 2007) Hinnouho (Whitehall Il study , 2015 ) Guo ( ARIC , 2016 )

Rishi (THIN, 2017)

Nathalie (NHS, 2018 )

Random effects model

Heterogeneity: $I^{2}=91 \%, \tau^{2}=0.1081, p<0.01$

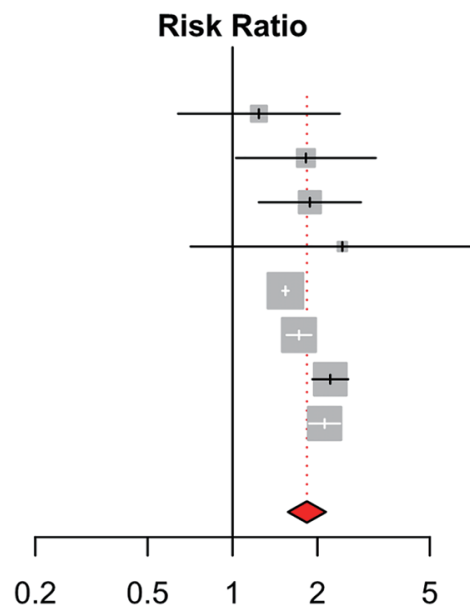

RR $\quad 95 \%-\mathrm{Cl}$ Weight

$1.24[0.64 ; 2.40] \quad 4.4 \%$

$1.82[1.03 ; 3.22] \quad 5.5 \%$

$1.88[1.24 ; 2.85] \quad 8.5 \%$

$2.45[0.71 ; 8.45] \quad 1.5 \%$

$1.54[1.50 ; 1.58] \quad 22.1 \%$

$1.72[1.55 ; 1.90] \quad 20.2 \%$

$2.22[1.92 ; 2.57] \quad 18.5 \%$

$2.12[1.87 ; 2.41] \quad 19.3 \%$

$1.83[1.57 ; 2.14] 100.0 \%$

\section{RR $\quad 95 \%-\mathrm{Cl}$ Weight}

$1.74 \quad[1.05 ; 2.88] \quad 16.3 \%$

$2.05[1.29 ; 3.26] \quad 17.6 \%$

$3.92[1.19 ; 12.93] \quad 5.0 \%$

$1.51[1.47 ; 1.55] \quad 31.6 \%$

$2.27 \quad[1.96 ; 2.62] 29.4 \%$

$1.93[1.44 ; 2.58] 100.0 \%$

RR $\quad 95 \%-\mathrm{Cl}$ Weight

$1.49[0.86 ; 2.58] \quad 17.9 \%$

$2.15 \quad[1.12 ; 4.13] \quad 15.2 \%$

$3.87[1.17 ; 12.79] \quad 6.9 \%$

$1.56 \quad[1.52 ; 1.60] \quad 30.8 \%$

2.58 [2.22; 3.00$] 29.2 \%$

$2.00[1.40 ; 2.87] 100.0 \%$

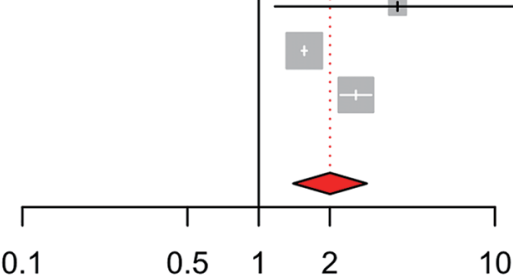

Figure 3 Meta-analyses of metabolically unhealthy body mass index categories for the risk of stroke compared with MH-NW individuals. (A) Metabolically unhealthy normal weight; (B) metabolically unhealthy overweight; (C) metabolically unhealthy obese. ARIC, Atherosclerosis Risk in Communities Study; THIN, The Health Improvement Network; NHIS-NSC, National Health Insurance Service-National Sample Cohort; NHS, Nurses' Health Study; CHRLS, China Health and Retirement Longitudinal Study; MH-NW, metabolically healthy normal weight. 
the weight status.

Obesity has been considered as an indicator of poor health. However, a concept of "obesity paradox" has recently emerged, which is used to describe the unexpected improvement in prognosis and reduction in mortality found in several diseases among patients with higher body weight (28-30). A meta-analysis showed that MHO population had a higher risk of cardiovascular events (stroke was considered as one of the outcomes) over the long term, which indicated that the duration of follow-up is a critical element in evaluating low-risk populations for future events (31). Partially consistent with previous studies, our analyses found, even not considering the effects of followup, the risk of stroke in $\mathrm{MHO}$ individuals was still higher than that of MH-NW individuals, suggesting that there is no "healthy" pattern of obesity. Some previous reports only assessed MHO individuals over short term $(32,33)$ or compared these individuals with controls without cardiovascular risk (32), which may lead to the "obesity paradox". Our study once again refuted the view that high BMI may be harmless.

In addition, special attention should be paid to MU$\mathrm{HW}$ individuals. Although the risk of stroke in the $\mathrm{MHO}$ group was increased, it was still lower than that of MU-NW participants, suggesting intermediate risk. Indeed, the MUHW group had a similar risk compared with MU-OW and MUO groups. A possible explanation is that even without excess weight, this group may represent the most severe subtype in the phenotypic profile of individuals genetically predisposed to cardiovascular disease, so they have unfavorable metabolic characteristics. The study reported that compared with the MH-NW group, MU-HW group had the highest weighted differences in LDL cholesterol and glucose levels (even higher than their overweight and obese peers with unhealthy metabolism) (31).

Previous meta-analyses evaluating the association between BMI and the risk of stroke have not considered the presence of metabolic factors $(5,34,35)$. The advantage of this study is that the large sample size can well reflect BMI and metabolic status, which allows us to determine reliable risk estimates related to the six BMI-metabolism categories.

\section{Limitations}

It is worth noting that this study has some limitations. First, most of studies used BMI to define obesity. Although waist circumference might more accurately depict an individual's visceral obesity (36), waist circumference values were not available from the database. What's more, weight gain is an essential risk factor, often accompanied by the progression of abnormal metabolic status. However, there were no studies reporting data on BMI changes during follow-up time. It is possible that BMI changes, rather than weight status at the time of data collection, impact stroke risk more profoundly (16). Besides, the study has shown that non-Hispanic black population had a higher rate of $\mathrm{MHO}$, suggesting that ethnic background may be an important factor in determining MHO (37). However, due to the lack of information from original studies, we did not carry out detailed studies of different races.

\section{Future directions}

In the future, detailed studies should be conducted for individuals of different ethnic backgrounds. The dynamic changes of participants' BMI, waist circumference and other indicators should be regularly followed up in more in-depth research.

\section{Conclusions}

In conclusion, this meta-analysis of prospective studies showed that obese individuals with metabolic phenotypes considered to be 'healthy' still had a higher risk of stroke compared with $\mathrm{MH}-\mathrm{NW}$ individuals. Existing prospective evidence does not indicate that healthy obesity is a harmless condition. Weight reduction and improvements in health are needed and they are beneficial to reducing the risk of stroke for MHO individuals.

\section{Acknowledgments}

Funding: This study was supported by grants from the Taishan Scholar Program of Shandong Province (ts201511109 and tsqn20161079) and Qingdao Key Health Discipline Development Fund, Shanghai Municipal Science and Technology Major Project (No. 2018SHZDZX01) and ZHANGJIANG LAB, Tianqiao and Chrissy Chen Institute, and the State Key Laboratory of Neurobiology and Frontiers Center for Brain Science of Ministry of Education, Fudan University.

\section{Footnote}

Reporting Checklist: The authors have completed the PRISMA reporting checklist. Available at http://dx.doi. 


\section{Page 10 of 11}

org/10.21037/atm-20-4387

Conflicts of Interest: All authors have completed the ICMJE uniform disclosure form (available at http://dx.doi. org/10.21037/atm-20-4387). The authors have no conflicts of interest to declare.

Ethical Statement: The authors are accountable for all aspects of the work in ensuring that questions related to the accuracy or integrity of any part of the work are appropriately investigated and resolved.

Open Access Statement: This is an Open Access article distributed in accordance with the Creative Commons Attribution-NonCommercial-NoDerivs 4.0 International License (CC BY-NC-ND 4.0), which permits the noncommercial replication and distribution of the article with the strict proviso that no changes or edits are made and the original work is properly cited (including links to both the formal publication through the relevant DOI and the license). See: https://creativecommons.org/licenses/by-nc-nd/4.0/.

\section{References}

1. Collaborators GCoD. Global, regional, and national agesex specific mortality for 264 causes of death, 1980-2016: a systematic analysis for the Global Burden of Disease Study 2016. Lancet 2017;390:1151-210.

2. Lee SW, Kim HC, Lee HS, et al. Thirty-Year Trends in Mortality from Cerebrovascular Diseases in Korea. Korean Circ J 2016;46:507-14.

3. Eckel RH, Grundy SM, Zimmet PZ. The metabolic syndrome. Lancet 2005;365:1415-28.

4. Finucane MM, Stevens GA, Cowan MJ, et al. National, regional, and global trends in body-mass index since 1980: systematic analysis of health examination surveys and epidemiological studies with 960 country-years and 9.1 million participants. Lancet 2011;377:557-67.

5. Chen W, Pan Y, Jing J, et al. Association of Body Mass Index and Risk of Stroke After Acute Minor Stroke or TIA: a Post Hoc Analysis of a Randomized Controlled Trial. Neurotox Res 2019;36:836-43.

6. Doehner W, Schenkel J, Anker SD, et al. Overweight and obesity are associated with improved survival, functional outcome, and stroke recurrence after acute stroke or transient ischaemic attack: observations from the TEMPiS trial. Eur Heart J 2013;34:268-77.

7. Park H, Lee HW, Yoo J, et al. Body Mass Index and

\section{Ma et al. Metabolically healthy obesity (MHO) and risk of stroke}

Prognosis in Ischemic Stroke Patients With Type 2

Diabetes Mellitus. Front Neurol 2019;10:563.

8. Kwon BJ, Kim DW, Her SH, et al. Metabolically obese status with normal weight is associated with both the prevalence and severity of angiographic coronary artery disease. Metabolism 2013;62:952-60.

9. Aguilar-Salinas CA, Garcia EG, Robles L, et al. High adiponectin concentrations are associated with the metabolically healthy obese phenotype. J Clin Endocrinol Metab 2008;93:4075-9.

10. Ogorodnikova AD, Kim M, McGinn AP, et al. Incident cardiovascular disease events in metabolically benign obese individuals. Obesity (Silver Spring) 2012;20:651-9.

11. Ortega FB, Lee DC, Katzmarzyk PT, et al. The intriguing metabolically healthy but obese phenotype: cardiovascular prognosis and role of fitness. Eur Heart J 2013;34:389-97.

12. Primeau V, Coderre L, Karelis AD, et al. Characterizing the profile of obese patients who are metabolically healthy. Int J Obes (Lond) 2011;35:971-81.

13. Hinnouho GM, Czernichow S, Dugravot A, et al. Metabolically healthy obesity and risk of mortality: does the definition of metabolic health matter? Diabetes Care 2013;36:2294-300.

14. Thomsen M, Nordestgaard BG. Myocardial infarction and ischemic heart disease in overweight and obesity with and without metabolic syndrome. JAMA Intern Med 2014;174:15-22.

15. Andersen SS, Andersson C, Berger SM, et al. Impact of metabolic disorders on the relation between overweight/ obesity and incident myocardial infarction and ischaemic stroke in fertile women: a nationwide cohort study. Clin Obes 2015;5:127-35.

16. Caleyachetty R, Thomas GN, Toulis KA, et al. Metabolically Healthy Obese and Incident Cardiovascular Disease Events Among 3.5 Million Men and Women. J Am Coll Cardiol 2017;70:1429-37.

17. McInnes MDF, Moher D, Thombs BD, et al. Preferred Reporting Items for a Systematic Review and Metaanalysis of Diagnostic Test Accuracy Studies: The PRISMA-DTA Statement. JAMA 2018;319:388-96.

18. Stroup DF, Berlin JA, Morton SC, et al. Meta-analysis of observational studies in epidemiology: a proposal for reporting. Meta-analysis Of Observational Studies in Epidemiology (MOOSE) group. JAMA 2000;283:2008-12.

19. Stang A. Critical evaluation of the Newcastle-Ottawa scale for the assessment of the quality of nonrandomized studies in meta-analyses. Eur J Epidemiol 2010;25:603-5.

20. Higgins JP, Thompson SG, Deeks JJ, et al. Measuring 
inconsistency in meta-analyses. BMJ 2003;327:557-60.

21. Eckel N, Meidtner K, Kalle-Uhlmann T, et al. Metabolically healthy obesity and cardiovascular events: A systematic review and meta-analysis. Eur J Prev Cardiol 2016;23:956-66.

22. Song Y, Manson JE, Meigs JB, et al. Comparison of usefulness of body mass index versus metabolic risk factors in predicting 10-year risk of cardiovascular events in women. Am J Cardiol 2007;100:1654-8.

23. Hinnouho GM, Czernichow S, Dugravot A, et al. Metabolically healthy obesity and the risk of cardiovascular disease and type 2 diabetes: the Whitehall II cohort study. Eur Heart J 2015;36:551-9.

24. Guo F, Garvey WT. Cardiometabolic disease risk in metabolically healthy and unhealthy obesity: Stability of metabolic health status in adults. Obesity (Silver Spring) 2016;24:516-25.

25. Eckel N, Li Y, Kuxhaus O, et al. Transition from metabolic healthy to unhealthy phenotypes and association with cardiovascular disease risk across BMI categories in 90257 women (the Nurses' Health Study): 30 year follow-up from a prospective cohort study. Lancet Diabetes Endocrinol 2018;6:714-24.

26. Lee HJ, Choi EK, Lee SH, et al. Risk of ischemic stroke in metabolically healthy obesity: A nationwide populationbased study. PLoS One 2018;13:e0195210.

27. Li H, He D, Zheng D, et al. Metabolically healthy obese phenotype and risk of cardiovascular disease: Results from the China Health and Retirement Longitudinal Study. Arch Gerontol Geriatr 2019;82:1-7.

28. Curtis JP, Selter JG, Wang Y, et al. The obesity paradox: body mass index and outcomes in patients with heart failure. Arch Intern Med 2005;165:55-61.

29. Fleischmann E, Teal N, Dudley J, et al. Influence of excess

Cite this article as: Ma LZ, Sun FR, Wang ZT, Tan L, Hou XH, Ou YN, Dong Q, Yu JT, Tan L. Metabolically healthy obesity and risk of stroke: a meta-analysis of prospective cohort studies. Ann Transl Med 2021;9(3):197. doi: 10.21037/atm-204387 weight on mortality and hospital stay in 1346 hemodialysis patients. Kidney Int 1999;55:1560-7.

30. Gruberg L, Weissman NJ, Waksman R, et al. The impact of obesity on the short-term and long-term outcomes after percutaneous coronary intervention: the obesity paradox? J Am Coll Cardiol 2002;39:578-84.

31. Kramer CK, Zinman B, Retnakaran R. Are metabolically healthy overweight and obesity benign conditions?: A systematic review and meta-analysis. Ann Intern Med 2013;159:758-69.

32. Hamer M, Stamatakis E. Metabolically healthy obesity and risk of all-cause and cardiovascular disease mortality. J Clin Endocrinol Metab 2012;97:2482-8.

33. Voulgari C, Tentolouris N, Dilaveris P, et al. Increased heart failure risk in normal-weight people with metabolic syndrome compared with metabolically healthy obese individuals. J Am Coll Cardiol 2011;58:1343-50.

34. Duan D, Li H, Xu J, et al. Does Body Mass Index and Height Influence the Incident Risk of Ischemic Stroke in Newly Diagnosed Type 2 Diabetes Subjects? J Diabetes Res 2019;2019:2591709.

35. Rodriguez-Castro E, Rodriguez-Yanez M, Arias-Rivas S, et al. Obesity Paradox in Ischemic Stroke: Clinical and Molecular Insights. Transl Stroke Res 2019;10:639-49.

36. Benjamin EJ, Virani SS, Callaway CW, et al. Heart Disease and Stroke Statistics-2018 Update: A Report From the American Heart Association. Circulation 2018;137:e67-e492.

37. Zheng R, Zhou D, Zhu Y. The long-term prognosis of cardiovascular disease and all-cause mortality for metabolically healthy obesity: a systematic review and meta-analysis. J Epidemiol Community Health 2016;70:1024-31. 


\section{Supplementary}

Table S1 Quality evaluation of included studies

\begin{tabular}{|c|c|c|c|c|c|c|c|c|c|}
\hline Study & $\mathrm{S} 1$ & S2 & S3 & S4 & C & O1 & $\mathrm{O} 2$ & $\mathrm{O} 3$ & Sum \\
\hline Hinnouho, 2015 & $\star$ & $\star$ & $\star($ Laboratory tests) & $\star$ & $\star \star$ & $\star$ & $\star(17.4)$ & $-(\mathrm{NA})$ & 8 \\
\hline Andersen, 2015 & $\star$ & $\star$ & $\star($ Interview $)$ & $\star$ & $\star \star$ & $\star$ & $\star(5.6)$ & $-(\mathrm{NA})$ & 8 \\
\hline Guo, 2016 & $\star$ & $\star$ & $\star$ (Laboratory tests) & $\star$ & $\star \star$ & $\star$ & $\star(18.7)$ & $-(\mathrm{NA})$ & 8 \\
\hline Lee, 2018 & $\star$ & $\star$ & $\star($ Laboratory tests) & $\star$ & $\star \star$ & $\star$ & $\star(7.4)$ & $-(\mathrm{NA})$ & 8 \\
\hline Nathalie, 2018 & - & $\star$ & $\star$ (Questionnaires) & $\star$ & $\star \star$ & $\star$ & $\star(24)$ & $\star(74.2 \%)$ & 8 \\
\hline Li, 2019 & $\star$ & $\star$ & $\star($ Laboratory tests) & $\star$ & $\star \star$ & $\star$ & $-(3.6)$ & $-(\mathrm{NA})$ & 7 \\
\hline
\end{tabular}

We herein selected "age, gender" as the most important adjusting factors. A mean follow-up duration of at least 5 years was predefined as long enough for outcome to occur in our study. It was regarded as adequate when the follow-up rate was at least $70 \%$. NA: not available; S1: Representativeness of the exposed cohort; S2: Selection of the non-exposed cohort; S3: Ascertainment of exposure; S4: Demonstration that outcome of interest was not present at start of study; C: Comparability of cohorts on the basis of the design or analysis; O1: Assessment of outcome; O2: Was follow-up long enough for outcomes to occur?; O3: Adequacy of follow up of cohorts. 
Metabolically Healthy (heterogeneity: $l^{2}=36 \%, P=0.14$ )

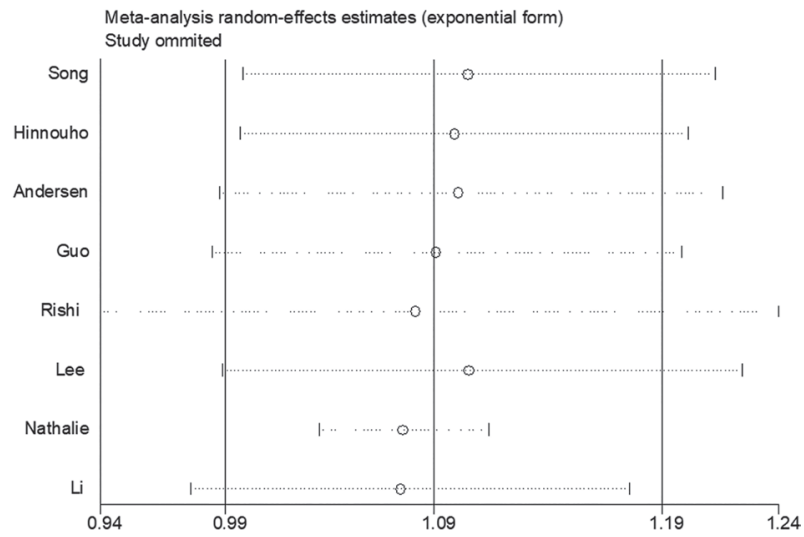

Metabolically Unhealthy Normal Weight (heterogeneity: $\mathrm{I}^{2}=86 \%, \mathrm{P}<0.01$ )

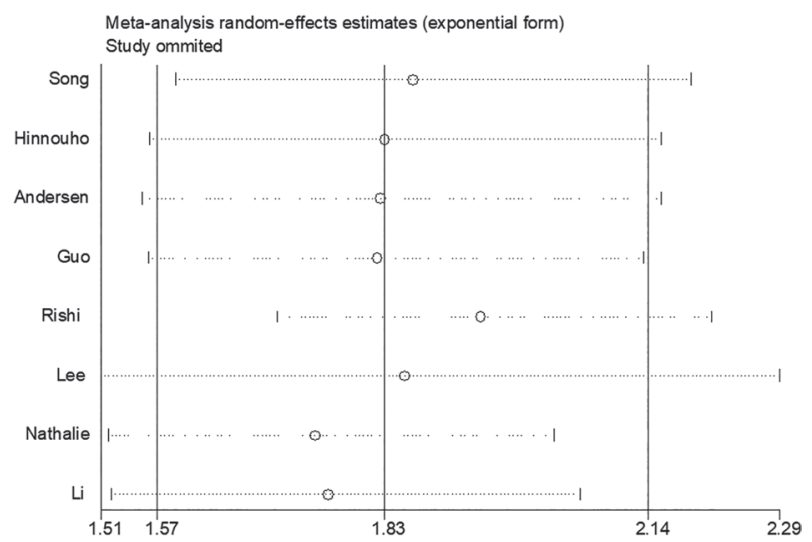

Metabolically Unhealthy Obese (heterogeneity: $I^{2}=91 \%, P<0.01$ )

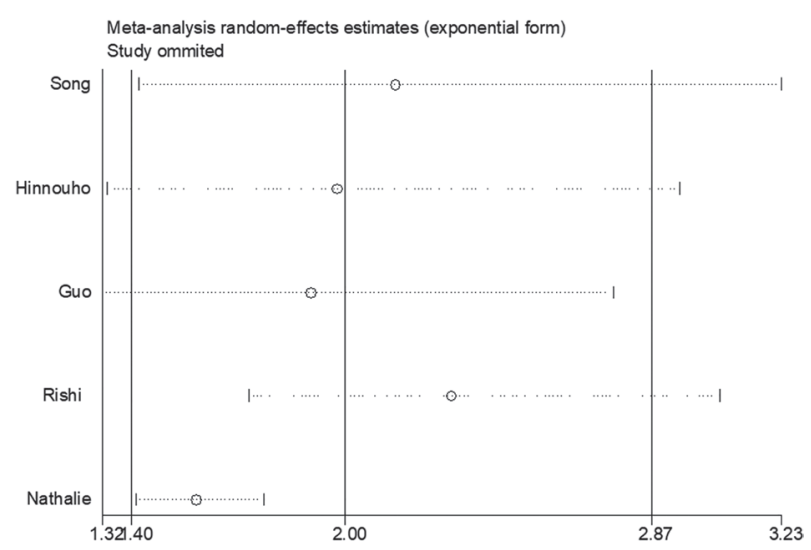

Figure S1 Results of sensitivity analysis after excluding one single study.

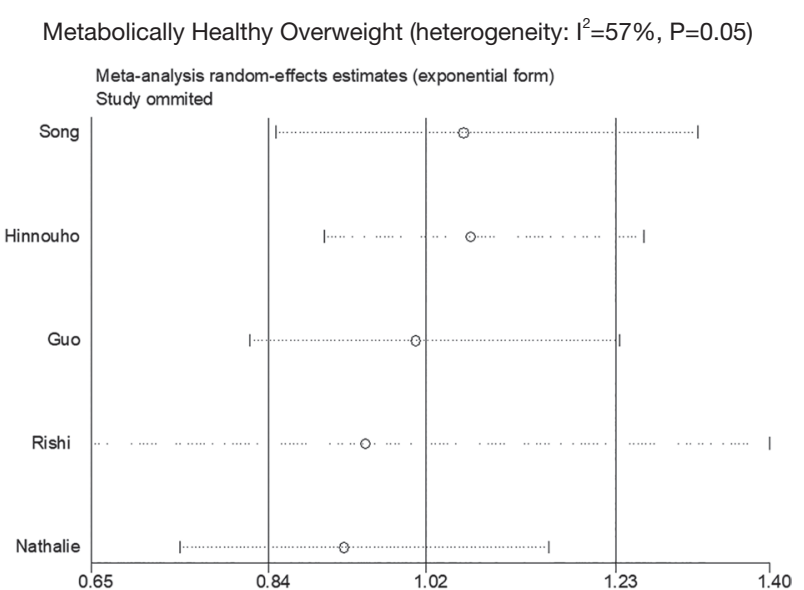

Metabolically Unhealthy Overweight (heterogeneity: $\mathrm{I}^{2}=88 \%, \mathrm{P}<0.01$ )

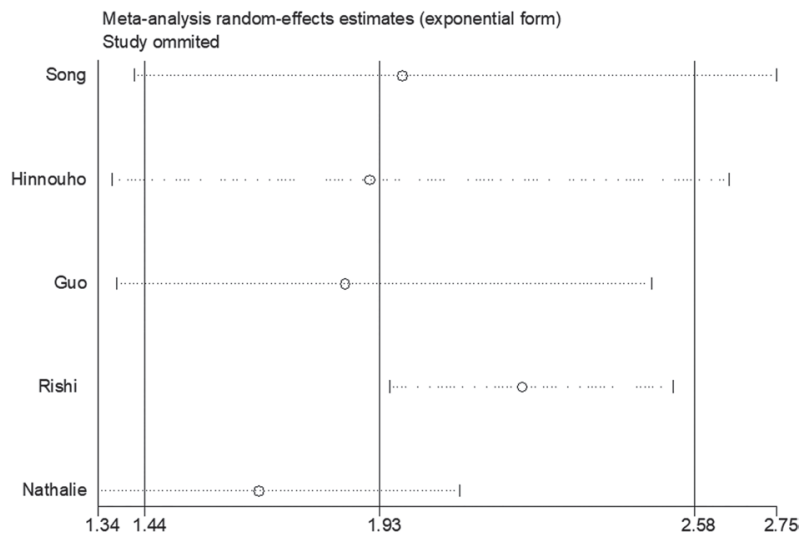


A Study

Subgroup $=$ Follow - up time $>10$ years Hinnouho (Whitehall II study, 2015)

Guo ( ARIC , 2016)

Nathalie ( NHS , 2018)

Fixed effect model

Random effects model

Heterogeneity: $I^{2}=65 \%, \tau^{2}=0.1597, p=0.06$

B

Song (Women's Health Study, 2007 )

Rishi (THIN, 2017)

Fixed effect model

Random effects model

Heterogeneity: $I^{2}=28 \%, \tau^{2}=0.0066, p=0.24$

Fixed effect model

Random effects model

Heterogeneity: $I^{2}=57 \%, \tau^{2}=0.0208, p=0.05$

Residual heterogeneity: $I^{2}=57 \%, p=0.07$

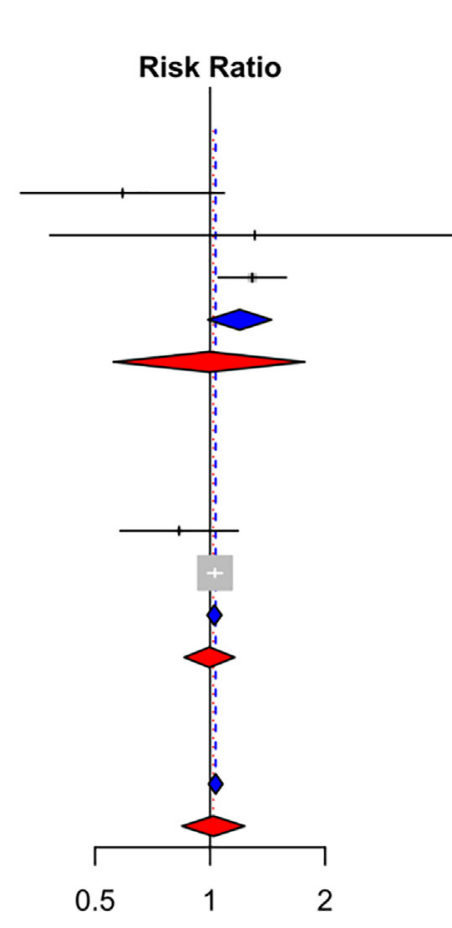

$0.59 \quad[0.32 ; 1.09]$

$1.31[0.38 ; 4.50]$

$1.29[1.05 ; 1.58]$

$1.20[0.99 ; 1.45]$

$0.99[0.56 ; 1.77]$

$0.5 \% \quad 7.8 \%$

$0.1 \% \quad 2.2 \%$

$4.3 \% \quad 29.2 \%$

$4.9 \%$

-- $\quad 39.3 \%$

$0.83[0.58 ; 1.18] \quad 1.4 \% \quad 17.3 \%$

$1.03[0.99 ; 1.08] \quad 93.6 \% \quad 43.4 \%$

$1.03[0.98 ; 1.07] \quad 95.1 \%$

$1.00[0.86 ; 1.16] \quad--\quad 60.7 \%$

$1.03[0.99 ; 1.08] 100.0 \%$

$1.02[0.84 ; 1.23] \quad--100.0 \%$

Figure S2 Subgroup analyses' results of the Metabolically Healthy Overweight phenotype.

\section{A Study}

Subgroup $=$ Follow - up time $>10$ years

Hinnouho (Whitehall II study, 2015)

Guo ( ARIC , 2016)

Nathalie (NHS, 2018)

Fixed effect model

Random effects model

Heterogeneity: $I^{2}=0 \%, \tau^{2}=0, p=0.54$

B Subgroup $=$ Follow-up time $\leq 10$ years

Song (Women's Health Study, 2007 )

Rishi (THIN, 2017)

Fixed effect model

Random effects model

Heterogeneity: $I^{2}=0 \%, \tau^{2}=0, p=0.91$

\section{Fixed effect model}

\section{Random effects model}

Heterogeneity: $I^{2}=0 \%, \tau^{2}=0, p=0.67$

Residual heterogeneity: $I^{2}=0 \%, p=0.74$

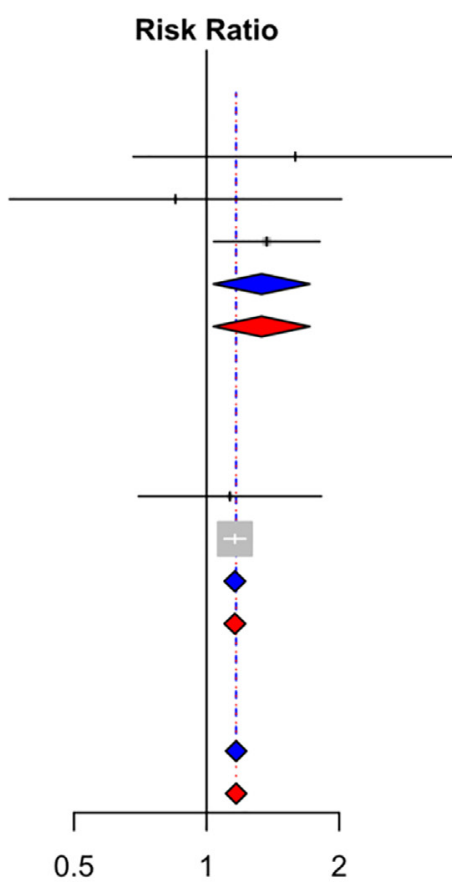

RR

$1.59[0.68 ; 3.71]$

$0.85[0.36 ; 2.02]$

$1.37[1.04 ; 1.81]$

$1.33[1.04 ; 1.72]$

$1.33[1.04 ; 1.72]$

Weight Weight

(fixed) (random)

$0.4 \%$

$0.4 \%$

$3.8 \%$

$4.6 \%$

$--$

$0.4 \%$

$0.4 \%$

$3.8 \%$

$--$

$4.6 \%$

$1.13[0.70 ; 1.82] \quad 1.3 \% \quad 1.3 \%$

$1.16[1.10 ; 1.23] \quad 94.1 \% \quad 94.1 \%$

$1.16[1.10 ; 1.23] \quad 95.4 \%$

$1.16[1.10 ; 1.23] \quad--\quad 95.4 \%$

$1.17[1.11 ; 1.23] 100.0 \%$

$1.17[1.11 ; 1.23] \quad--\quad 100.0 \%$

Figure S3 Subgroup analyses' results of the Metabolically Healthy Obesity phenotype. 


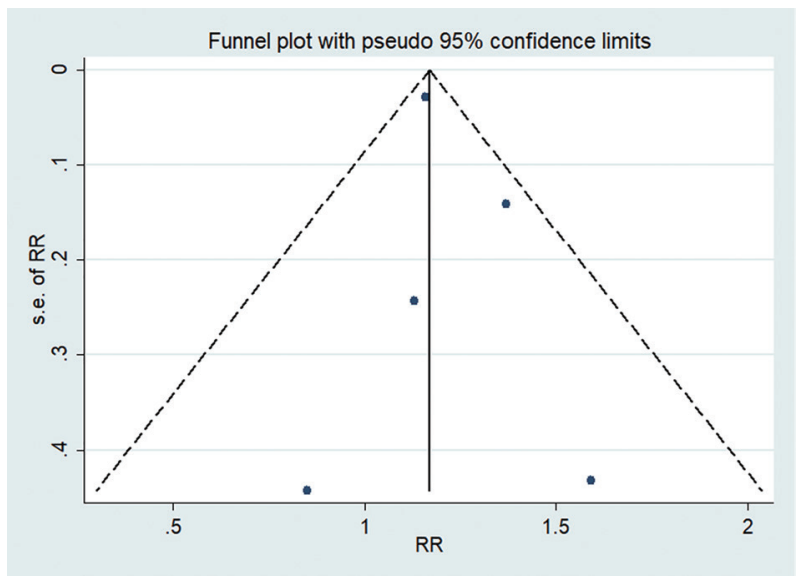

Figure S4 The funnel plot of studies assessing the association between MHO group and the risk of stroke.

\begin{tabular}{|c|c|c|c|}
\hline \multicolumn{4}{|l|}{ MHO group and risk of stroke compared to MHNW for Stroke } \\
\hline \multicolumn{4}{|l|}{$\begin{array}{l}\text { Patient or population: Stroke } \\
\text { Setting: } \\
\text { Intervention: MHO group and risk of stroke } \\
\text { Comparison: MHNW }\end{array}$} \\
\hline Outcomes & $\begin{array}{l}\text { NNe of participants } \\
\text { (studies) } \\
\text { Follow up }\end{array}$ & $\begin{array}{l}\text { Certainty of the } \\
\text { evidence } \\
\text { (GRADE) }\end{array}$ & $\begin{array}{l}\text { Relative effect } \\
(95 \% \mathrm{CI})\end{array}$ \\
\hline RR & ( 5 observational studies) & $\bigoplus \bigoplus \bigoplus \bigcirc$ & $\begin{array}{l}\text { RR } 1.17 \\
(1.11 \text { to } 1.23)\end{array}$ \\
\hline \multicolumn{4}{|c|}{$\begin{array}{l}\text { "The risk in the intervention group (and its } 95 \% \text { confidence interval) is based on the assumed risk in the comparison group and the relative effect of the intervention (and its } 95 \% \mathrm{Cl} \text { ). } \\
\mathrm{Cl} \text { : Confidence interval; RR: Risk ratio }\end{array}$} \\
\hline \multicolumn{4}{|c|}{$\begin{array}{l}\text { GRADE Working Group grades of evidence } \\
\text { High certainty: We are very confident that the true effect lies close to that of the estimate of the effect } \\
\text { Moderate certainty: We are moderately confident in the effect estimate: The true effect is likely to be close to the estimate of the effect, but there is a possibility that it is substantially different } \\
\text { Low certainty: Our confidence in the effect estimate is limited: The true effect may be substantially different from the estimate of the effect } \\
\text { Very low certainty: We have very little confidence in the effect estimate: The true effect is likely to be substantially different from the estimate of effect }\end{array}$} \\
\hline
\end{tabular}

Figure S5 The credibility of result categorized with GRADEpro GDT. 
Table S2 Factors with a change of statistical significance after conducting sensitivity analysis

\begin{tabular}{|c|c|c|c|c|c|c|c|c|}
\hline $\begin{array}{l}\text { Body mass index- } \\
\text { metabolic status } \\
\text { phenotypes }\end{array}$ & Result & $\mathrm{RR}$ & $\mathrm{LCl}$ & $\mathrm{UCl}$ & $1^{2}$ & $\mathrm{P}$ & $\begin{array}{l}\text { Possible source of } \\
\text { heterogeneity }\end{array}$ & $\begin{array}{l}\text { A or } B \\
\text { is more } \\
\text { credible }\end{array}$ \\
\hline $\begin{array}{l}\text { Metabolically Healthy } \\
\text { and } \mathrm{BMI} \geq 25 \mathrm{~kg} / \mathrm{m}^{2}\end{array}$ & $\begin{array}{l}\text { Result after excluding Nathalie } \\
\text { Eckel (2018) }\end{array}$ & 1.07 & 1.04 & 1.11 & $0 \%$ & 0.55 & $\begin{array}{l}\text { The diagnosis of } \\
\text { metabolic abnormalities } \\
\text { is not based on } \\
\text { laboratory tests }\end{array}$ & $B$ \\
\hline \multirow{2}{*}{$\begin{array}{l}\text { Metabolically Healthy } \\
\text { Overweight }\end{array}$} & Primary result & 1.02 & 0.84 & 1.23 & $57 \%$ & 0.05 & & \\
\hline & $\begin{array}{l}\text { Result after excluding Nathalie } \\
\text { Eckel (2018) }\end{array}$ & 0.93 & 0.74 & 1.16 & $36 \%$ & 0.20 & $\begin{array}{l}\text { The diagnosis of } \\
\text { metabolic abnormalities } \\
\text { is not based on } \\
\text { laboratory tests }\end{array}$ & B \\
\hline $\begin{array}{l}\text { Metabolically } \\
\text { Unhealthy Normal } \\
\text { Weight }\end{array}$ & $\begin{array}{l}\text { Result after excluding Rishi } \\
\text { Caleyachetty (2017) }\end{array}$ & 1.95 & 1.71 & 2.22 & $52 \%$ & 0.05 & $\begin{array}{l}\text { The diagnosis of } \\
\text { metabolic abnormalities } \\
\text { is not based on } \\
\text { laboratory tests }\end{array}$ & B \\
\hline \multirow{2}{*}{$\begin{array}{l}\text { Metabolically } \\
\text { Unhealthy Overweight }\end{array}$} & Primary result & 1.93 & 1.44 & 2.58 & $88 \%$ & $<0.01$ & & \\
\hline & $\begin{array}{l}\text { Result after excluding Rishi } \\
\text { Caleyachetty (2017) }\end{array}$ & 2.23 & 1.95 & 2.54 & $0 \%$ & 0.58 & $\begin{array}{l}\text { The diagnosis of } \\
\text { metabolic abnormalities } \\
\text { is not based on } \\
\text { laboratory tests }\end{array}$ & B \\
\hline
\end{tabular}

BMI, body mass index; A, the primary result; B, the result after excluding one literature;RR, risk factor; LCl, low confidence interval; UCI, upper confidence interval. 